Portland State University

PDXScholar

\title{
A Comprehensive Examination of Electronic Wayfinding Technology for Visually Impaired Travelers in an Urban Environment
}

Martin Swobodzinski

Portland State University, swobod@pdx.edu

Amy T. Parker

Portland State University, atp5@pdx.edu

Follow this and additional works at: https://pdxscholar.library.pdx.edu/trec_reports

Part of the Transportation Commons, Urban Studies Commons, and the Urban Studies and Planning Commons

Let us know how access to this document benefits you.

\section{Recommended Citation}

Swobodzinski, Martin. \& Parker, Amy T. A Comprehensive Examination of Electronic Wayfinding Technology for Visually Impaired Travelers in an Urban Environment: Final Report. NITC-RR-1177. Portland, OR: Transportation Research and Education Center (TREC), 2019. https://doi.org/10.15760/ trec. 227

This Report is brought to you for free and open access. It has been accepted for inclusion in TREC Final Reports by an authorized administrator of PDXScholar. Please contact us if we can make this document more accessible: pdxscholar@pdx.edu. 


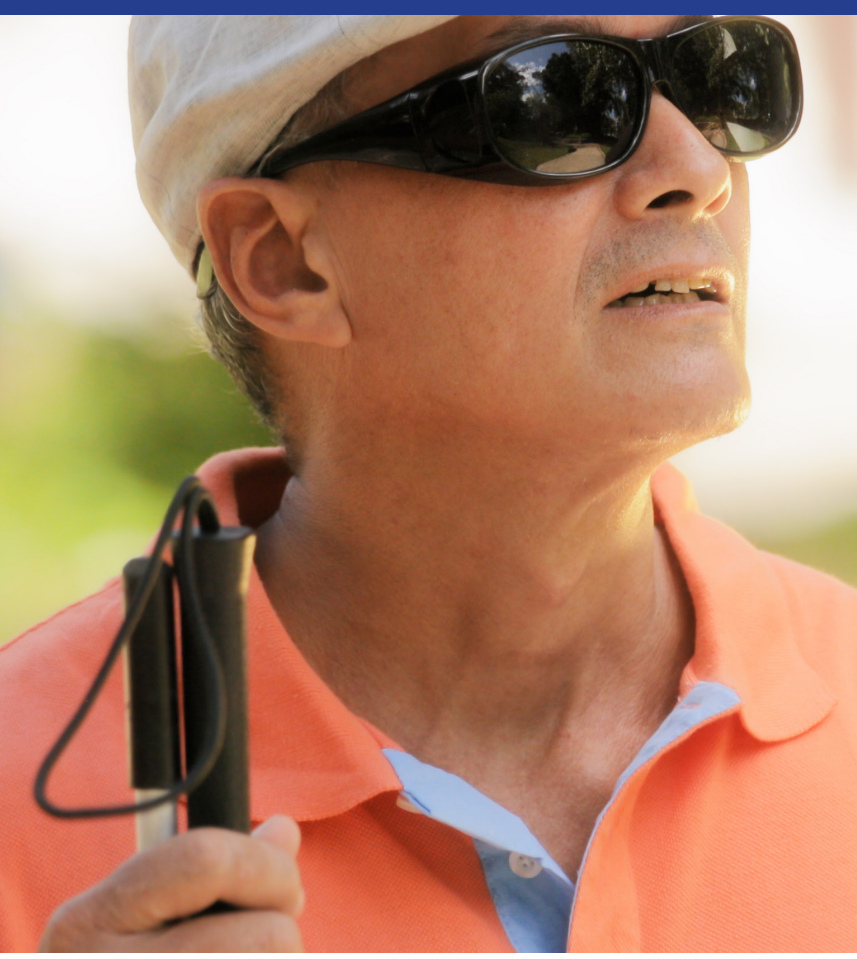

\section{A Comprehensive Examination of Electronic Wayfinding Technology for Visually Impaired Travelers in an Urban Environment}

Martin Swobodzinski, Ph.D. Amy T. Parker, EdD, COMS

की Portland State 


\section{A Comprehensive Examination of Electronic Wayfinding Technology for Visually Impaired Travelers in an Urban Environment}

Final Report

\section{NITC-RR-1177}

by

Martin Swobodzinski

Portland State University

and

Amy T. Parker

Portland State University

for

National Institute for Transportation and Communities (NITC)

P.O. Box 751

Portland, OR 97207
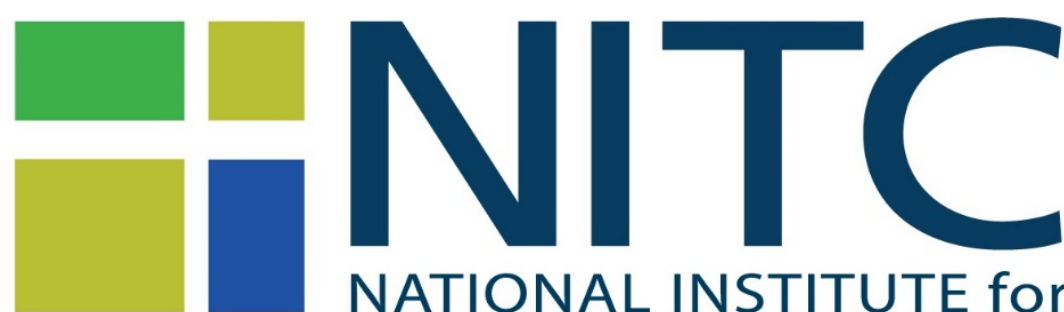

NATIONAL INSTITUTE for

TRANSPORTATION and COMMUNITIES

August 2019 


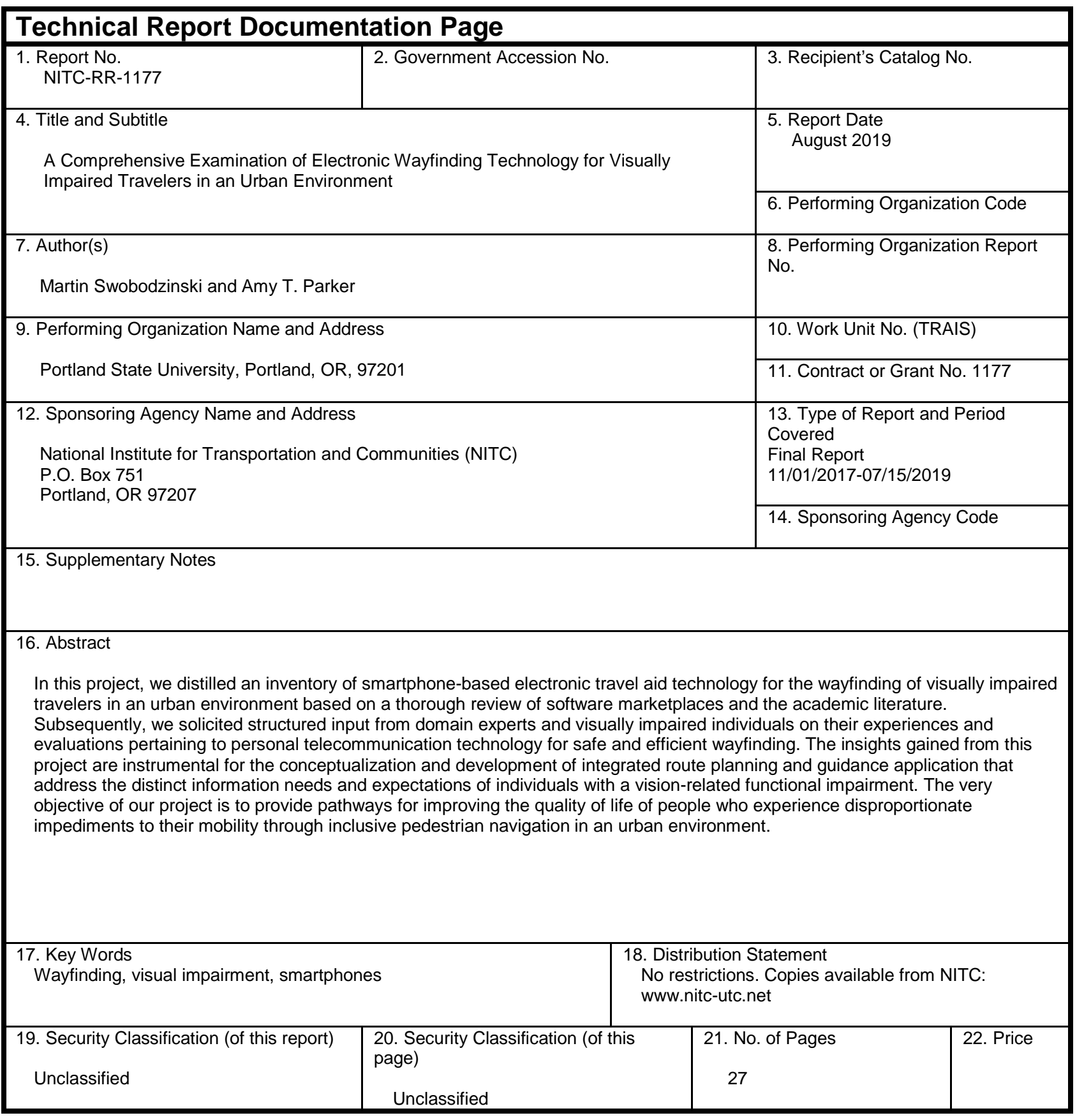




\section{ACKNOWLEDGEMENTS}

The authors would like to acknowledge partial support from the National Institute for Transportation and Communities (NITC; grant number 1177), a U.S. DOT University Transportation Center, and the National Science Foundation (NSF; Grant number BCS123456).

\section{DISCLAIMER}

The contents of this report reflect the views of the authors, who are solely responsible for the facts and the accuracy of the material and information presented herein. This document is disseminated under the sponsorship of the U.S. Department of Transportation University Transportation Centers Program in the interest of information exchange. The U.S. Government assumes no liability for the contents or use thereof. The contents do not necessarily reflect the official views of the U.S. Government. This report does not constitute a standard, specification, or regulation.

\section{RECOMMENDED CITATION}

Swobodzinski, Martin. \& Parker, Amy T. A Comprehensive Examination of Electronic Wayfinding Technology for Visually Impaired Travelers in an Urban Environment: Final Report. NITC-RR-1177. Portland, OR: Transportation Research and Education Center (TREC), 2019. 
TABLE OF CONTENTS

EXECUTIVE SUMMARY

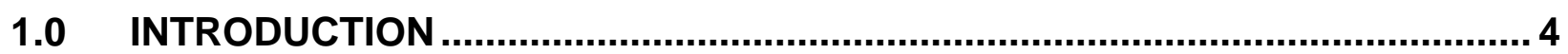

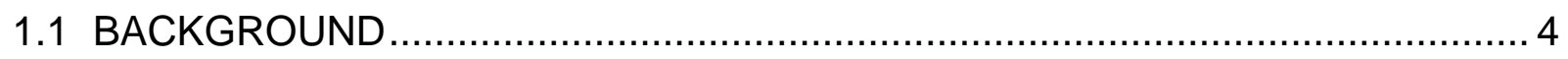

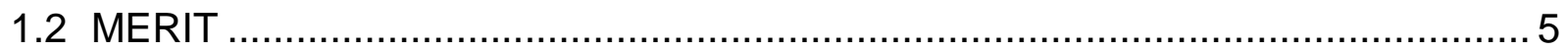

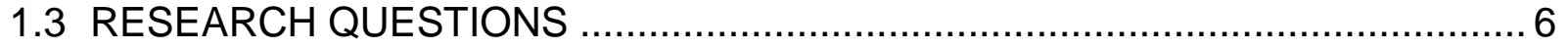

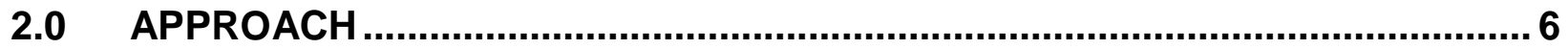

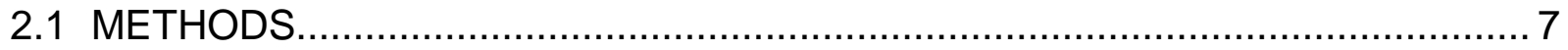

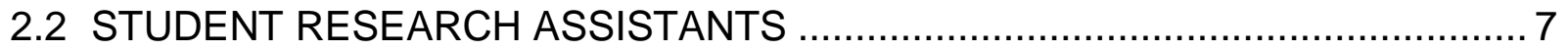

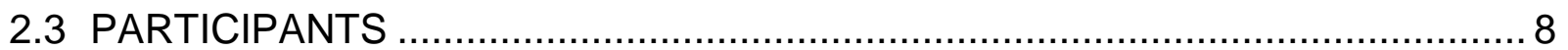

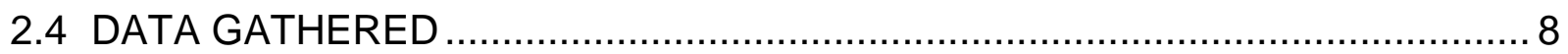

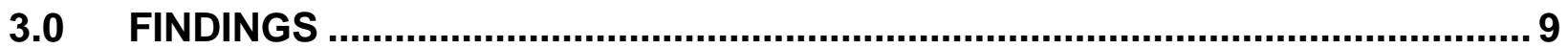

3.1 LITERATURE AND MARKETPLACE REVIEW .......................................... 9

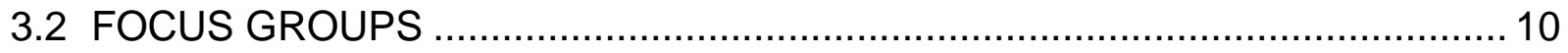

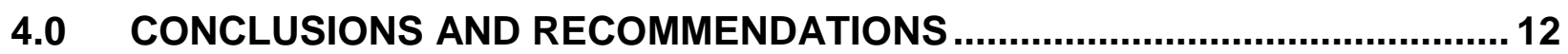

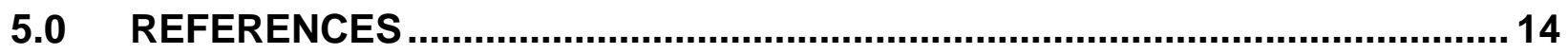

APPENDICES

APPENDIX A-1: ANNOTATED REVIEW OF APPS

\section{LIST OF TABLES}

Table 3.1: Categorization of Mobile Wayfinding Apps for Visually Impaired Pedestrian Travelers ........................................................................................... 10 Table 3.2: Comparison of Topic Items Discussed during Focus Group Sessions: Apps,

Devices, and Assistive Software ............................................................... 11 Table 3.3: Comparison of Topic Items Discussed during Focus Group Sessions: Desires 


\section{EXECUTIVE SUMMARY}

In this project, we distilled an inventory of state-of-the-art travel aid technology for the wayfinding of visually impaired travelers in an urban environment based on a thorough review of software marketplaces and the academic literature. Subsequently, we solicited structured input from domain experts and visually impaired individuals on evaluation criteria to assess the suitability of personal telecommunication technology for the safe and efficient wayfinding of visually impaired users. Our study was based on a multipronged, sequential approach that involved an extensive review of the academic literature and mobile software marketplaces, on the one hand, and focus groups with domain experts as well as focus groups with individuals who are visually impaired, blind, or deaf-blind. Project activities took place over an 18-month time frame.

The very objective of our project is to provide pathways for the improvement of the mobility of people who experience impediments to their mobility due to a functional impairment through a better understanding of the state and suitability of currentgeneration personal navigation and digital mapping technologies. In doing so, our project aids in the subversion of prevailing normative assumptions about technologyassisted individual travel and helps empower visually-impaired individuals which, in turn, we expect to contribute to the formation of stronger, inclusive communities.

\subsection{INTRODUCTION}

As it stands, individuals with a visual impairment as well as those with combined vision and hearing loss constitute a sizable, growing minority of the general population. These individuals experience disproportionate impediments to their mobility, with oftentimes large ramifications on their access to communal resources and events, opportunities for social interaction, quality of life, and overall health (Wilson et al. 2017). Smartphonebased travel aids have yet to be systematically evaluated regarding the degree to which the special information needs and expectation of visually impaired users are met so that these individuals can reap the same benefits that such technology affords for the general population.

\subsection{BACKGROUND}

Smartphones and digital mapping applications play an ever-increasing role in the everyday life of large parts of the population. A prime use for these mobile devices and respective software applications is to help individuals to navigate the environment efficiently and safely. The Pew Research Center (2015) estimated that two-thirds of the U.S. population are smartphone users, with comparatively higher levels of use among 
adults below the age of 30 and those with low household incomes. Two-thirds of smartphone owners reported that they at least occasionally used their smartphone for navigation-related activities, in particular in the context of car-based travel (e.g., turn-byturn instructions, public transit information, reserve a taxi or car service). At the same time, we witness increasing numbers in regard to the percentages of the population with a functional impairment, with current overall estimates for the U.S. at 22\%: $13 \%$ mobility, $10.6 \%$ cognition, $6.5 \%$ independent living, $4.6 \%$ vision, $3.6 \%$ self-care (Courtney-Long et al, 2015). In a recent study of 259 visually impaired individuals (Kane et al., 2009), the use rate of mobile wayfinding apps was $13 \%$, which makes it a distant third behind the $29.4 \%$ of users of visual identification apps (29.4\%) and the $20.4 \%$ of users of screen reading and writing apps (but ahead of leisure reading apps at $13 \%$ and news apps at 7.7\%). Given the stark differences among the use patterns between the sighted and the visually impaired, it stands to reason that the progressing proliferation of mobile technologies with their focus on able-bodied digital natives bears risks of exclusion and marginalization, in particular of populations with a form of impairment. The very functionality of these highly dynamic technologies and their frequent reliance on a visuo-haptic modality of user interaction inhibits, if not prevents, individuals with visual impairments from experiencing the same degree of usefulness and convenience as the sighted users of these technologies.

More recently, attention has been placed on the development of smartphone-based technologies to facilitate visually impaired users in their wayfinding activities (Coughlan and Manduchi, 2009; Kane et al., 2009; Narasimhan et al., 2009; Swobodzinski and Raubal, 2009; Zöllner et al., 2011; Ahmetovic, 2013; Hakobyan et al., 2013; Caldini et al., 2015; Diamantatos and Kavallieratou, 2014; Ye et al., 2014; Griffin-Shirley et al., 2017). A widely under-explored component in these works, however, is the empirical assessment of smartphone-based wayfinding technologies in terms of their usefulness (i.e., the degree to which a product enables a user to achieve his or her goals, which includes the user's intrinsic motivation) and usability (i.e., the degree to which a product is able or fit to be used) of these technologies (Davis, 1989) for visually impaired users, which is particularly relevant for the study at hand.

\subsection{MERIT}

The proposed research and its anticipated deliverables strongly resonate NITC's theme of improving the mobility of people and goods to build strong communities. It is well established that activity and mobility are directly linked to the well-being of a community. The rapidly progressing dissemination of personal mobile technologies and travel applications affords greater representation and ease of travel for various demographics, in particular those who are referred to as digital natives. However, given that the occurrence of functional impairments is positively correlated to age, it stands to reason that such progressing dissemination also drives forward the exclusion of various populations by its very focus on visual and haptic modalities of interaction and normative assumptions about the physical abilities of the user that the technology is serving. In addition, many of the software developments and innovations related to personal electronic travel aids are driven forward by actors in the industry, which 
presumably does not facilitate a particular emphasis on segments of the population other than the mainstream.

\subsection{RESEARCH QUESTIONS}

In this project we aimed at unpacking the challenges and opportunities that arise from the emergence of affordable mobile telecommunication devices and their adoption by the visually impaired community. More specifically, we distilled an inventory of state-ofthe-art mobile technology for the wayfinding of visually impaired travelers in an urban environment. To the extent that prior reviews have described the landscape of mobile assistive technology for the visually impaired (Kane et al., 2009; Griffin-Shirley et al., 2017), our work focused on the formulation of criteria and scales for an empirical evaluation of assistive wayfinding technologies in terms of their usability and usefulness as perceived by visually impaired users.

The central research questions for our project were:

- Which mobile wayfinding apps garner use by visually impaired travelers in an urban environment?

- In which way can contemporary mobile telecommunication devices and mobile wayfinding apps be best leveraged to ease mobility impediments of individuals with a visual impairment?

\subsection{APPROACH}

Throughout the duration of our project, we were able to leverage and expand our connections with national, regional, and local advocacy organizations for the visually impaired, blind, and deaf-blind community. In particular, we established professional contacts and repeat communication with the American Printing House for the Blind $(\mathrm{APH})$, the Accessibility Division at Microsoft, the Seattle Lighthouse for the Blind, the Seattle Deaf-Blind Service Center, and the Oregon Commission for the Blind. This approach reflects our commitment to embed and conduct our research with and within the very population of interest. Fostering strong relationships, connections, and partnerships were and are key to the progression, acceptance, and continuation of our research. It also provides a foundation for participatory partnerships for implementing future research findings within national, state and local communities.

A major community-outreach accomplishment, which was led by Co-PI Parker in partnership with colleagues at the Transportation Research and Education Center (TREC), was the successful planning and execution of the Mobility Matters summit in March 2018 and 2019 during which the PI Swobodzinski and Co-I Parker presented on the project to a mostly non-academic audience of sighted, blind, deaf-blind, and visually impaired members of the community, Orientation and Mobility specialists, and transportation planners. Our 2019 research talk was done collaboratively in a joint 
session with our partners at APH. Leading up to Mobility Matters 2019, PI Swobodzinski was invited as a panelist to the first Accessible Indoor Navigation Symposium at APH.

\subsection{METHODS}

Our project employed a two-prong research approach comprised of the following main elements: 1) a structured literature and digital marketplace review of smartphone-based wayfinding apps and related technology and 2) focus groups with blind, deafblind, and visually-impaired participants as well as professional Orientation and Mobility instructors. The combination of Orientation and Mobility specialists (being those individuals who formally instruct visually-impaired, blind, and deaf-blind individuals as it comes to wayfinding and orientation, among others skills), visually impaired and blind individuals, and deaf-blind individuals provide the basis for a culturally relevant comparative study. The primary goal of our analysis is to better understand, by comparing and contrasting, in which way mobile wayfinding technology is employed by Orientation \& Mobility instructors, visually-impaired and blind individuals, and those individuals who are deaf-blind.

A secondary goal is to begin to describe the experiences of travelers with visual impairments or deaf-blindness in using available wayfinding apps in their everyday travel routines. In this way, the structured review of the existing wayfinding apps and technologies, which were designed for individuals with visual impairments, could be further contextualized with input from focus groups of travelers and professionals who use such technologies in their everyday lives. Using more than one method to respond to the research questions afforded the research team a type of methodological triangulation, a quality indicator for producing descriptive knowledge of phenomena (Brantlinger et al., 2005). Initial content analysis across sources portrays a landscape of wayfinding apps that is grounded in the literature and the lived experiences of individuals who are visually impaired or deaf-blind.

\subsection{STUDENT RESEARCH ASSISTANTS}

In the winter term 2018, we leveraged Dr. Parker's (Co-I) research methods class and brought on board two graduate students in the PSU Orientation and Mobility program. Under the supervision of Dr. Parker, these two students engaged in a preliminary literature review and a draft of an IRB application for our project as a part of their deliverables for Dr. Parker's research methods class. Throughout this process, class expectations and project requirements were openly and frequently communicated with the two students. In consultation with PSU library staff, the research team used designated search terms and four databases including IEEE Xplore, Google Scholar, Web of Science, and Engineering Village to cull studies for analysis. In addition, over the summer term 2019, we hired a graduate research assistant to aid in expanding the inventory of mobile wayfinding apps and related non-mobile wayfinding technology through an assessment of the academic literature and electronic mobile marketplaces, and specifically Google Play and the iTunes store. In addition, we worked jointly with these individuals on the transcription and interpretation of focus group recordings, as described further below. 


\subsection{PARTICIPANTS}

Based on IRB-approved protocols, we conducted a total of four focus groups, as follows: one focus group at PSU with three Orientation and Mobility Specialists, one with four Orientation and Mobility specialists at the Oregon Commission for the Blind, one with eight visually impaired and blind individuals at the Oregon Commission for the Blind, and one with nine deaf-blind individuals at the Seattle Deaf-Blind Service Center. Participants were recruited through invitational flyers through agencies and focus groups were arranged at convenient times for the participants as to not disrupt class or work schedules. Participants were offered a modest Amazon gift card for their time in contributing to the focus groups. Participants communicated with researchers using spoken English or manually using close-range American Sign Language or tactile sign language. From the purposive sample, ten women and fourteen men elected to participate in the focus groups. Of the twenty-four focus group participants, two were of Asian descent, two African-American, one Middle-Eastern, one Latino, and eighteen were Caucasian.

\subsection{DATA GATHERED}

The data that we gathered during the focus groups were audio recordings of those with visually-impaired and blind participants as well as Orientation \& Mobility specialists. For the focus group with deaf-blind participants, we relied on video recordings, given that the modality of communication among deaf-blind participants was based on close range visual or tactile sign language. That is, the deaf-blind person puts his or her hands over the signer's hands to feel the shape, movement and location of the signs. It is important to note that in consultation with the Seattle Deaf-Blind Service Center, individuals worked communication facilitation in small groups using tactile or close range American Sign Language for participants to ensure that the research questions and small group discussion was fully accessible to all participants. The audio and video recordings were subsequently transcribed to text, either manually by reviewing the video content or through online transcription services for audio files. Dr. Parker and two student researchers, all fluent in American Sign Language, created transcripts from the videorecorded focus groups and reviewed the video and written transcripts for accuracy individually and as a research team. A transcription service was used to convert the audio-recorded focus groups. Dr. Swobodzinski and student researchers reviewed the audio and the written transcripts for accuracy before beginning the coding process. The duration of each focus group was approximately one hour and participants were asked a set of six IRB-approved questions.

Responses were analyzed using constant comparison techniques (Lincoln and Guba, 1985) and coded for themes by the lead and student researchers. In order to ensure quality, the research team employed member checks to ensure that participants' voices were represented authentically and accurately. The researchers encouraged participants to offer any additional insights via email after the focus groups. Three participants chose to share additional thoughts via email and these were incorporated into the transcript analysis process. 
In alignment with constant comparison processes, the team parsed words, sentences and phrases from transcripts into categories iteratively. Once final code categories were assigned, the lead researchers, Swobodzinski and Parker, re-coded transcripts, discussed any agreements or disagreements, and formulated responses/themes in tables. Quotes from participants were drawn out that reflected gestalt themes across participant groups.

\subsection{FINDINGS}

\subsection{LITERATURE AND MARKETPLACE REVIEW}

The objective of the review was to determine what kinds of design elements visually impaired users prefer in smartphone wayfinding applications. In order to contextualize user feedback found in articles, participant characteristics were extracted to determine existing patterns in research. Heterogeneity is a hallmark of the visually impaired population; age of onset, etiology, and various other demographic information plays a significant role in how the visually impaired person engages with the world around them, and is critical to understand when analyzing feedback from users. Understanding who is providing feedback on these applications is crucial for detailing which applications work best for individuals with low vision, blindness, or those with additional visual needs. However, participant data was not reported consistently across articles, and in some cases was excluded entirely.

In reviewing available wayfinding applications and navigation tools, it is clear that there are gaps in the technology that allow for limited accessibility for those who are blind or who have low vision. One such gap that is frequently cited is the inability for many applications to provide navigation seamlessly from outdoor use to indoor use and vice versa. These transitions can be disorienting for a person without usable vision. Furthermore, the cost of apps and the potential need for additional hardware can prove to be a barrier for those who do not have the financial means to obtain these navigation systems.

What seems to be major shortcomings of many of these apps are intersection navigation and the final stretch of navigation to a desired location. Many navigation apps rely on GPS which is not always accurate for those who do not have usable vision. GPS will direct a traveler to a location within a few yards, but then the traveler has to locate the exact stop on their own beyond that point. This can lead to frustrating and even potentially dangerous situations for the blind or visually impaired traveler. When navigating intersections, many apps - especially those that rely on GPS - can cause the traveler to get turned around or disoriented, as the app may confuse the traveler's trajectory. GPS is not the only issue as our infrastructure is made for sighted individuals and not always adapted for the needs of the visually impaired. These concerns indicate a need for both infrastructure and navigation applications to work in synchrony. GPS may not be the most reliable source of wayfinding, but combined with additional 
supports, visually impaired travelers may be able to navigate more safely and accurately.

Another gap that the review captured is that there were almost no references to individuals who are deaf-blind. The wayfinding apps, associated technologies, and explorations of efficacy did not address the unique travel needs of this population.

Table 3.1: Categorization of Mobile Wayfinding Apps for Visually Impaired Pedestrian Travelers

\begin{tabular}{|c|c|c|c|c|c|c|c|c|c|c|c|}
\hline \multirow[b]{2}{*}{ Application Name } & \multicolumn{3}{|c|}{ Cost } & \multicolumn{3}{|c|}{ Wayfinding Support } & \multicolumn{3}{|c|}{ Operating System } & \multicolumn{2}{|c|}{ Additional Hardware Needed? } \\
\hline & High & Low & Free & Indoor & Outdoor & Both & iOS & Android & Both & Yes & No \\
\hline Aira & $\mathrm{X}$ & & & & & $\mathrm{X}$ & & & $\mathrm{X}$ & $\mathrm{X}^{s}$ & \\
\hline Apple Maps & & & $\mathrm{X}$ & & $\mathrm{X}$ & & $\mathrm{X}$ & & & & \\
\hline Ariadne & & $\mathrm{X}$ & & & $\mathrm{X}$ & & $\mathrm{X}$ & & & & $\mathrm{X}$ \\
\hline Arianna & & & $\mathrm{X}$ & $\mathrm{X}$ & & & & & $\mathrm{X}$ & $\mathrm{X}^{c}$ & \\
\hline Autour & & & $\mathrm{X}$ & & $\mathrm{X}$ & & $\mathrm{X}$ & & & $\mathrm{x}^{h}$ & \\
\hline Aware & & & $\mathrm{X}$ & $\mathrm{X}$ & & & & & $\mathrm{X}$ & $\mathrm{X}^{b}$ & \\
\hline Be My Eyes & & & $\mathrm{X}$ & & & $\mathrm{X}$ & & & $\mathrm{X}$ & & $\mathrm{X}$ \\
\hline BeAware & & & $\mathrm{X}$ & & & $\mathrm{X}$ & $\mathrm{X}$ & & & $\mathrm{X}^{b}$ & \\
\hline Blind Explorer & & & $\mathrm{X}$ & & $\mathrm{X}$ & & & $\mathrm{X}$ & & $\mathrm{X}^{h}$ & \\
\hline BlindSquare & $\mathrm{X}$ & & & & & $\mathrm{X}$ & $\mathrm{X}$ & & & & $\mathrm{X}$ \\
\hline BlindWays & & & $\mathrm{X}$ & & $\mathrm{X}$ & & $\mathrm{X}$ & & & & $\mathrm{X}$ \\
\hline Click and Go Navigation & & & $\mathrm{X}$ & & & $\mathrm{X}$ & $\mathrm{X}$ & & & & $\mathrm{X}$ \\
\hline DotWalker & & & $\mathrm{X}^{*}$ & & $\mathrm{X}$ & & & $\mathrm{X}$ & & & $\mathrm{X}$ \\
\hline Eye-d & & $\mathrm{X}$ & $\mathrm{X}$ & & & $\mathrm{X}$ & & & $\mathrm{X}$ & $\mathrm{X}^{k}$ & \\
\hline FAR Vision & & & $\mathrm{X}^{* *}$ & & & $\mathrm{X}$ & & & $\mathrm{X}$ & $X^{b}$ & \\
\hline GetThere & & & $\mathrm{X}$ & & $\mathrm{X}$ & & & & $\mathrm{X}$ & & $\mathrm{X}$ \\
\hline Google Maps & & & $\mathrm{X}$ & & $\mathrm{X}$ & & & & $\mathrm{X}$ & & $\mathrm{X}$ \\
\hline Indoo.rs & & & $\mathrm{X}$ & $\mathrm{X}$ & & & $\mathrm{X}$ & & & $X^{b}$ & \\
\hline Lazarillo GPS & & & $\mathrm{X}$ & & $\mathrm{X}$ & & & & $\mathrm{X}$ & & $X$ \\
\hline Nearby Explorer & $\mathrm{X}$ & & & & $\mathrm{X}$ & & & & $\mathrm{X}$ & & $X$ \\
\hline NowNav & & $\mathrm{X}$ & & & $\mathrm{X}$ & & & $\mathrm{X}$ & & & \\
\hline Right-Hear & & & $\mathrm{X}$ & $\mathrm{X}$ & & & & & $\mathrm{X}$ & $x^{b}$ & \\
\hline Seeing Eye GPS & $\mathrm{X}$ & & & & $\mathrm{X}$ & & $\mathrm{X}$ & & & & $X$ \\
\hline Soundscape & & & $X$ & & $\mathrm{X}$ & & $\mathrm{X}$ & & & $\mathrm{x}^{h}$ & \\
\hline Talking Goggles & & $\mathrm{X}$ & & & & $\mathrm{X}$ & & & $\mathrm{X}$ & & $\mathrm{X}$ \\
\hline Wayfindr & $\mathrm{X}$ & & & $\mathrm{X}$ & & & & & $\mathrm{X}$ & $\mathrm{x}^{b}$ & \\
\hline
\end{tabular}

\subsection{FOCUS GROUPS}

The shortcomings with navigation apps identified by the academic literature and digital marketplace review were further supported by the testimony of the focus groups conducted among visually impaired individuals and professionals in the field of 
Orientation and Mobility. Further concerns were indicated by these participants. As many navigation apps have downfalls, it appears that blind travelers use multiple sources as a means of navigation. Many apps were identified as being used simultaneously for different aspects of the journey (i.e., BlindSquare used for intersection navigation in combination with Apple or Google maps for wayfinding). Several participants noted that an app that identifies streets or landmarks as they are passing by while on public transportation would be helpful. Further suggestions for improvements were the addition of turn-by-turn navigation, notification of road closures or obstacles in the path, and clear descriptions of intersections. Individual participants who are deaf-blind repeatedly expressed a desire for apps to support the meaningful interpretation of environmental sounds into haptic or visual notifications safety. In reflecting on the street crossing task, individuals with combined vision and hearing loss suggested that apps that could offer information specific sounds such as the presence of emergency vehicles would greatly enhance their safety.

Table 3.2: Comparison of Topic Items Discussed during Focus Group Sessions: Apps, Devices, and Assistive Software

\begin{tabular}{|c|c|c|c|}
\hline Discussed in Focus Groups & O\&MSpecialists & Visually Impaired/Blind & Deaf-Blind \\
\hline \multirow[t]{21}{*}{ Apps } & Apple Maps & Apple Maps & Apple Maps \\
\hline & Aira & & \\
\hline & & & $\mathrm{AT} \& \mathrm{~T}$ \\
\hline & Be My Eyes & Be My Eyes & \\
\hline & & & Google Earth \\
\hline & BlindSquare & BlindSquare & \\
\hline & Google Maps & Google Maps & Google Maps \\
\hline & & & iMove \\
\hline & Lazarillo & & \\
\hline & & Lyft/Uber & Lyft/Uber \\
\hline & & Moovit & Moovit \\
\hline & Nearby Explorer & & \\
\hline & & & One Bus Away \\
\hline & PDX Bus & PDX Bus & \\
\hline & Seeing AI & & Seeing AI \\
\hline & & & SenseNav \\
\hline & Siri & Siri & \\
\hline & Soundscape & Soundscape & \\
\hline & & & Transit App \\
\hline & & Trip Planner & Trip Planner \\
\hline & & & Waze \\
\hline \multirow[t]{12}{*}{ Devices } & Android & & \\
\hline & & & Apple Watch \\
\hline & Bluetooth & & \\
\hline & BrailleNote (Touch) & & Braille Interface \\
\hline & & & Guiding Robots \\
\hline & & Headphones & \\
\hline & iBeacons & & \\
\hline & & iPad & iPad \\
\hline & & iPhone & IPhone/6 \\
\hline & Miniguide & & \\
\hline & RFID & & \\
\hline & Trekker Breeze & & \\
\hline \multirow[t]{3}{*}{ Assistive Software } & Navigon & & \\
\hline & & JAWS & \\
\hline & & Zoomtext & \\
\hline
\end{tabular}


Table 3.3: Comparison of Topic Items Discussed during Focus Group Sessions: Desires

\begin{tabular}{|c|c|c|c|}
\hline Discussed in Focus Groups & O\&M Specialists & Visually Imaired/Blind & Deaf-Blind \\
\hline \multirow[t]{9}{*}{ Desires } & Better integration of systems & The killer navigation app & $\begin{array}{c}\text { Integration instead of proliferation of } \\
\text { technologies }\end{array}$ \\
\hline & & $\begin{array}{c}\text { Alternative interfaces (spatial, non- } \\
\text { audio) }\end{array}$ & $\begin{array}{c}\text { Easy interface with braille; vibratory } \\
\text { features }\end{array}$ \\
\hline & & $\begin{array}{l}\text { Matched, exact information (transit, } \\
\text { rerouting, names of stops, alarms) }\end{array}$ & $\begin{array}{l}\text { Apps to translate sound information } \\
\text { for safety (sirens/alarms) }\end{array}$ \\
\hline & & $\begin{array}{l}\text { Seamless, real-time navigation } \\
\text { (landmarks, POIs, distance, time) }\end{array}$ & $\begin{array}{l}\text { Easy to enlarge, customize colors, and } \\
\text { scale; control glare }\end{array}$ \\
\hline & & Learn routes, reduce stress & \\
\hline & & Coverage in rural areas & \\
\hline & $\begin{array}{l}\text { Greater access to vendors; more } \\
\text { preparation and professional training }\end{array}$ & $\begin{array}{l}\text { Empathy, compassion, shared } \\
\text { experiences }\end{array}$ & \\
\hline & $\begin{array}{l}\text { Central repository for technology } \\
\text { information }\end{array}$ & & \\
\hline & Time to learn from each other & & \\
\hline & & & \\
\hline & & & \\
\hline
\end{tabular}

\subsection{CONCLUSIONS AND RECOMMENDATIONS}

Our technology review revealed that many apps have one or two areas of wayfinding that they focus on and few if any address the information needs of blind, visually impaired, and deaf-blind travelers across the complete trip. That is, 1) plan and book a trip, 2) travel to transit station, 3) ride bus/transit, 4) cross streets/intersections, 5) arrive at destination. In addition, it is apparent that the artificial separation between indoor and outdoor travel prevails, even as it comes to conceptualizations of the complete trip.

Qualitative approaches are useful in describing phenomena from the perspective of the participants. After conducting a systematic literature review, focus groups were used to contextualize and ground the findings, amplifying the voices of participants who are often marginalized in the design process. In this study, participants not only included adult travelers with visual impairment or deaf-blindness but also Orientation and Mobility specialists who shared perspectives on the use of wayfinding technologies as a part of 
their instructional practices with clients or students. Together the findings from the systematic review and the focus groups illuminate technological gaps as well as a lack of cohesive and integrated design approaches within the field of accessible wayfinding.

The suggestions by the focus group participants indicate a need for turn-by-turn, indoor/outdoor navigation that makes the journey and transitions between indoor and outdoor spaces as seamless as possible, from the planning stage and throughout the execution of one's preferred travel plan. Furthermore, the deaf-blind participants specifically elaborated on interface-related shortcomings of the wayfinding apps that they have access to, which suggest that impediments to accessibility in terms of wayfinding apps are more prominent for deaf-blind individuals than those without hearing and vision loss.

Using a systematic review, qualitative research methods, such as focus groups, and building community conversations through events like Mobility Matters, the researchers plan to subsequently design and deploy a survey that incorporates information from this initial study to include the perspectives of more travelers. The findings from this study will also inform investigations of technology supported wayfinding experiences in specific contexts such as urban university campuses or the use of public transportation options in urban environments.

Substantial research is required to further our understanding of the information needs for and expectations towards inclusive, efficient, seamless, and affordable mobile wayfinding technology that is geared to the specific preferences, abilities, and skills of individuals across the gamut of functional disability, with our project being one incremental contribution to that end. 


\subsection{REFERENCES}

Ahmetovic, D., 2013. Smartphone-assisted mobility in urban environments for visually impaired users through computer vision and sensor fusion, in: 2013 IEEE 14th International Conference on Mobile Data Management. Presented at the 2013 IEEE 14th International Conference on Mobile Data Management, pp. 15-18.

Brantlinger, E., Jimenez, R., Klingner, J., Pugach, M., Richardson, V., 2005. Qualitative Studies in Special Education. Exceptional Children, 71(2), 195-207.

Caldini, A., Fanfani, M., Colombo, C., 2015. Smartphone-based obstacle detection for the visually impaired, in: Image Analysis and Processing - ICIAP 2015, Lecture Notes in Computer Science. Presented at the International Conference on Image Analysis and Processing, Springer, Cham, pp. 480-488.

Coughlan, J., Manduchi, R., 2009. A mobile phone wayfinding system for visually impaired users. Assistive Technology Research Series 25, 849.

Courtney-Long, E.A., Carroll, D.D., Zhang, Q., et al., 2015. Prevalence of disability and disability type among adults, United States - 2013. MMWR Morb Mortal Wkly Rep 2015; 64: 777-783.

Davis, F.D., 1989. Perceived usefulness, perceived ease of use, and user acceptance of information technology. MIS Quarterly 13, 319-340.

Diamantatos, P., Kavallieratou, E., 2014. Android based electronic travel aid system for blind people, in: Artificial Intelligence Applications and Innovations, IFIP Advances in Information and Communication Technology. Presented at the IFIP International Conference on Artificial Intelligence Applications and Innovations, Springer, Berlin, Heidelberg, pp. 585-592.

Griffin-Shirley, N., Banda, D., M. Ajuwon, P., Cheon, J., Lee, J., Ran Park, H., N. Lyngdoh, S., 2017. A survey on the use of mobile applications for people who are visually impaired. Journal of Visual Impairment \& Blindness 111, 307-323.

Hakobyan, L., Lumsden, J., O'Sullivan, D., Bartlett, H., 2013. Mobile assistive technologies for the visually impaired. Survey of Ophthalmology 58, 513-528.

Kane, S.K., Jayant, C., Wobbrock, J.O., Ladner, R.E., 2009. Freedom to roam: A study of mobile device adoption and accessibility for people with visual and motor disabilities, in: Proceedings of the 11th International ACM SIGACCESS Conference on Computers and Accessibility, Assets '09. ACM, New York, NY, USA, pp. 115-122.

Lincoln, Y S., Guba, E.G., 1985. Naturalistic Inquiry. Newbury Park, CA: Sage.

Narasimhan, P., Gandhi, R., Rossi, D., 2009. Smartphone-based assistive technologies for the blind, in: Proceedings of the 2009 International Conference on Compilers, Architecture, and Synthesis for Embedded Systems, CASES '09. ACM, New York, NY, USA, pp. 223-232. 
Pew Research Center, 2015. The Smartphone Difference. Retrieved on 05/02/2017. Available online at: http://www.pewinternet.org/2015/04/01/us-smartphone-use-in-2015/

Swobodzinski, M., Raubal, M., 2009. An indoor routing algorithm for the blind:

Development and comparison to a routing algorithm for the sighted. International Journal of Geographical Information Science 23, 1315-1343.

Wilson, C., McColl, M., Zhang, F., McKinnon, P., 2017. Measuring integration of disabled persons: Evidence from Canada's Time Use Databases. Canadian Journal of Disability Studies, 6(1), 105-127.

Ye, H., Malu, M., Oh, U., Findlater, L., 2014. Current and future mobile and wearable device use by people with visual impairments, in: Proceedings of the SIGCHI Conference on Human Factors in Computing Systems, CHI '14. ACM, New York, NY, USA, pp. 3123-3132.

Zöllner M., Huber S., Jetter H.C., Reiterer H., 2011: NAVI - A Proof-of-concept of a mobile navigational aid for visually impaired based on the Microsoft Kinect. In: Campos, P., Graham, N., Jorge, J., Nunes, N., Palanque, P., Winckler, M. (Eds.), HumanComputer Interaction - INTERACT 2011. INTERACT 2011. Lecture Notes in Computer Science, 6949, Springer, Berlin. 


\title{
APPENDIX A-1: ANNOTATED REVIEW OF APPS
}

\author{
Wayfinding Apps
}

Aira. (n.d.). Aira. Retrieved on August 2, 2018 from: https://aira.io/

Aira is an augmented reality wayfinding technology that utilizes sighted professionals who are available to provide assistance to blind users. Users of Aira are required to have special smart glasses that pair with the Aira smartphone app. This app allows users to press a button on their cell phone that connects them with an Aira support person. The smart glasses allow the support professional to see the app user's surroundings and provide descriptions of their surroundings and support with any sightrelated necessity they may have. Aira has several usage plans that range from $\$ 89$ to \$329 per month depending upon the user's needs. The plan fee includes the smart glasses, data, hardware insurance, a training session, and access to professional assistance.

AppleVis. (n.d.). Nearby explorer [various messages]. Retrieved on July 16, 2018 from: https://www.applevis.com/apps/ios/travel/nearby-explorer

Nearby Explorer is an iOS app that can be used by Apple product users for wayfinding via environmental description. This app can be used with Android phones, though it appears that capabilities are limited. Users can select location-related options for what information they would like Nearby Explorer to share. Users have identified that they like the feature that Nearby Explorer can still operate while the user's phone is locked, while the downside to this app is noted to be the price.

Autour. (n.d.). Autour. Retrieved on August 2, 2018 from: http://autour.mcgill.ca/en/

Autour is an outdoor navigation app created in Canada. This app requires a set of headphones - bone-conducting or open air headphones are recommended. Autour allows the user to experience spacialized navigation. For instance, an individual will hear an announcement of a nearby location that appears to come from that exact location, giving the user a sense of distance and locality. Autour is currently available for iOS devices, and is in the working stages for Android.

Blind Explorer. (n.d.). Blind Explorer. Retrieved on August 16, 2018 from https://blindexplorer.com/en/

Blind Explorer is an app that provides sensory guidance to smartphone users. This app uses 3D sound production via the use of headphones - Blind Explorer suggests the use of their own bone-conduction headphones. The app relies on pre-set routes that are sourced from other users or programmed by the individual. This app was created in Madrid, Spain. This app is currently available for Android, but will be available on iOS devices soon. 
BlindSquare. (n.d.). BlindSquare. Retrieved on August 1, 2018 from http://www.blindsquare.com/about/

BlindSquare is an indoor and outdoor wayfinding app that is available in many different languages. It is only available for iOS devices at this time, and it costs the user a onetime fee of $\$ 39.99$.

Brauner, Diane. (2017). Aware app review: Indoor wayfinding app. Perkins School for the Blind.

Retrieved from http://www.perkinselearning.org/technology/posts/aware-app-review-indoorwayfinding-app\#

The Aware app is created by Sensible Innovations. It utilizes iBeacon technology to provide turn-by-turn navigation as recorded by an O\&M instructor. This is a free app that can be used with a screen reader. Aware can only be used with Sensible Innovations iBeacons, and is currently only usable indoor. Users select their beginning and end points to receive turn-by-turn directions.

ClickAndGo Wayfinding Maps, LLC. . (2014). Click and go navigation. ClickAndGo Wayfinding. Retrieved from http://www.clickandgomaps.com/clickandgo$\underline{\text { navigation/ }}$

ClickAndGo Navigation app utilizes a searchable library of narrative navigation routes based on venues. This app can be used both indoor and outdoor, and provides step-bystep navigation. This app also includes tools to help the users familiarize themselves with a venue ahead of time by providing virtual tours, detailed routes, and descriptions of intersections. The ClickAndGo Navigation app does not require iBeacon hardware, but can be advanced by its use.

Demmitt, Audrey. (2015). My experience with using the Be My Eyes app. Louisville, KY: American Foundation for the Blind, VisionAware. https://www.visionaware.org/blog/visually-impaired-now-what/my-experiencewith-using-the-be-my-eyes-app/12

Be My Eyes utilizes volunteers who meet via live video with the app user. The sighted volunteer helps the app user to identify objects and provide basic visual assistance. The writer (Audrey Demmitt) notes that Be My Eyes is easy to use. You download the app and select whether you are sighted or a blind user. The menu and options for Be My Eyes is audio for the user as it connects them to a volunteer from anywhere around the world.

DotWalker. (May 11, 2015). DotWalker. Retrieved from http://www.dotwalkerpro.com/dw/dotwalker en.html 
DotWalker is only available on Android devices, and requires the use of a Talkback screen reader. There are free and paid versions of this app available (DotWalker Pro \$6.99). The user generates places on the DotWalker app that are stored as Routes; when using the app for navigation, the user selects the stored location and the app assists in navigating to the selected point.

Foresight Augmented Reality (FAR). (2018). FAR for the visually impaired. Retrieved on August 17, 2018 from https://www.foresightar.com/for-visually-impaired.php

The FAR Vision app allows users to navigate their surroundings to locate FAR accessible business. These businesses will include beacons throughout their buildings to ensure safe and equal access to those who are blind or visually impaired.

Furthermore, FAR Beacons can be purchased by the app user and issued for personal use. These beacons can be purchased for $\$ 49.99$ a piece. The FAR app is free and available for both Android and IOS devices. The portability of the personal beacons can allow for the FAR app to be used both indoors and outdoors.

Google Play. (n.d.). GetThere GPS app for the blind [various messages]. Retrieved on July 31, 2018 from https://play.google.com/store/apps/details?id=com.LewLasher.getthere\&hl=en U $\underline{\mathrm{S}}$

GetThere is an audio navigation device that talks to the user before and after each intersection. Users can request their location at any time by shaking their device. GetThere will inform the user when they stray off track and provides detailed information for the user to return to their planned route. This app also provides users with details regarding surrounding cross streets and intersections. GetThere is programmed with various languages and can be used on any smart device. Some reviewers note that the GetThere app does not recognize short routes, which can be problematic when navigating short distances. The app appears to crash occasionally on Android devices. Despite these glitches, it appears that the app works better with newer Androids, and most reviewers like the product.

Google Play. (n.d.). Lazarillo GPS for Blind [various messages]. Google. Retrieved on August 1, 2018 from https://play.google.com/store/apps/details?id=com.lazarillo\&hl=en US

Lazarillo GPS is a free app that can be used on all smart devices. This app was designed considering the input of blind travelers. The GPS works while the screen is off, saving the battery of the device. Lazarillo provides the user with information regarding their surroundings, upcoming intersections and points of interest, and it functions like a radio - providing the user with the information about their surroundings as they walk. Lazarillo GPS communicates important information about locations, upcoming events, times of operation, etc. to improve access to services for the blind or visually impaired user. Users review the Lazarillo GPS app with high ratings - is has 4.5 out of 5 stars after 368 reviews. 
Google Play. (n.d.). Talking Goggles [various messages]. Google. Retrieved on August 1, 2018 from

https://play.google.com/store/apps/details?id=com.sparkling.goggles\&hl=en US

Talking Goggles can be used in video or photo mode to identify images and explain them to the user. This app can be used to identify street signs, logos, faces and other general items. This is a low-cost app at 99 cents that can be used both indoors and outdoors. It's primary use for wayfinding purposes is identifying signage. Some users had trouble with the app continuously loading but never processing an image, while others feel that the app is great. This was given an overall rating of 3 out of 5 stars on Google Play. It can be used on any smart device.

Holton, Bill. (2018). Built-in smartphone mapping apps from Google and Apple. American

Foundation for the Blind. Retrieved from http://www.afb.org/info/living-with-vision$\underline{\text { loss/ }}$ using-technology/smartphone-gps-navigation-for-people-with-visualimpairments/built-i n-smartphone-mapping-apps-from-google-and-apple/1235

Both Apple Maps and Google Maps can provide a current location for a user within 16 feet. These locations can be set and saved as a destination in the user's map, and both apps contain a compass to inform the user of their direction and trajectory. Both apps allow the user to search points of interest within the map app, which allows the user to identify new locations and travel routes. Apple Maps and Google offer turn-by-turn walking directions to the user, and they also provide public transportation navigation options so the user can locate the appropriate mode of transportation that will get them to their desired destination. Google Maps will generate public transportation routes automatically when searched as long as the company providing public transportation supplies their information to Google. When using Apple Maps, the user will have to also install the transportation app used by the public transit provider - this data will then be shared with Apple Maps once the transit app is downloaded.

Indoo.rs. (n.d.). Indoo.rs: Visually impaired. Indoo.rs GmbH. Retrieved on August 2, 2018 from:

\section{https://indoo.rs/solution/visually-impaired/}

Indoo.rs is an indoor navigation system that can be purchased by companies or organizations for use by their visiting patrons. This system requires beacons to be dispersed throughout buildings to guide navigation by cell phone app. Indoo.rs is currently only available on iOS devices. The cost of the app is free, but the company or organization pays for the beacons and installation. 
Jozuka, Emiko. (2016). It's up to developers to bring this amazing audio wayfinding app to blind

People. Motherboard, Vice Media, LLC. Retrieved from

https://motherboard.vice.com/en us/article/4xaavg/its-up-to-developers-to-bringthis-ama

Zing-audio-wayfinding-app-to-blind-people

Wayfindr began as a navigation app catered to the London underground system. This app utilizes Bluetooth beacons and special headphones that communicate audio instructions as they pass by the beacons. These instructions include information regarding where to go and when.

Keirnan, Tommy. (n.d.). Discovered Technologies presents: BlindSquare - The accessible GPS

app. Retrieved on August 1, 2018 from

https://discovertechnologies.com/blog/blindsquare-accessible-gps-app/

BlindSquare utilizes VoiceOver to allow users to navigate by listening and talking. It provides the user with directions and information regarding points of interest along the way. BlindSquare uses Foursquare and Open Street Maps receive information for the user. The app user can filter information that they would like to receive regarding points of interest. It is only available to those who use iOS systems.

Medcalf, Laura. (2017). Nearby Explorer app. Easter Seals Crossroads. Retrieved from https://www.eastersealstech.com/2017/09/07/nearby-explorer-app/

Nearby Explorer was initially created for Android phones, but is now accessible by iOS products as well. This app provides descriptive identification of the user's surroundings. It uses the phone's GPS and compass, displays high-contrast maps, and provides audio description of the maps. This app is enhanced by using Google Places and Foursquare data. Some downsides to the app include impacts to accuracy due to cloud cover or large buildings. This app is for use outdoors where maps and GPS service function undisrupted.

Mehr, Gill. (2017). GingerMind Technologie's Eye-d is tapping technology to empower the

visually impaired. YourStory Media Pvt. Ltd. Retrieved from https://yourstory.com/2017/10/gingermind-visually-impaired/

Eye-d is an artificial intelligence-based app that serves to assist visually impaired users in their daily life activities. This app was created and launched by GingerMind Technologies in Bangalore, India, and is available for both Android and iOS devices. Research was conducted with the collaboration of 10 visually impaired people. The app has an optional use of an additional keypad - valued at \$60 - that pairs with the user's smartphone. Eye-d has a variety of options that the user can choose from; these options can provide the user with information regarding their current location and 
surroundings, and assist in navigation and reading out text. This app has free versions and versions for sale.

Microsoft. (2018). Microsoft soundscape. Microsoft. Retrieved from https://www.microsoft.com/en-us/research/product/soundscape/

Soundscape is in its research stages. It will provide 3D audio cues to the user in order to enhance their typical travel. Soundscape tracks the movement of the user's phone using location and activity sensors. The user will have to use headphones with this app, but no additional hardware. This is a free app that is compatible with most iOS products.

MIT Technology Review (January 8, 2014). App turns smartphone into virtual cane for the blind.

Retrieved from https://www.technologyreview.com/s/523401/app-turnssmartphone-into-virtual-cane-for-the-blind/\#comments

The Arianna app is an indoor navigation system that utilizes colored tape paths throughout a building and the use of the smartphone's camera to guide the user based on the specified color path. Once the phone camera identifies the colored path, the phone vibrates in the users hand, indicating that they are on track.

Morris, Nadia. (January 30, 2017). AT\&T Foundry for Connected Health helps blind people

"see" with Aira wearables. AT\&T. Retrieved from http://about.att.com/ innovationblog/aira wearables

Aira has paired with AT\&T to present their smart glasses. AT\&T and Aira are working to create artificial intelligence to replace the humans who work in the Aira call centers as visual assistants. The idea is to teach Al to provide enough information that Aira users can have an $\mathrm{Al} /$ human assistant hybrid to assist them with visual needs.

Perkins School for the Blind. (2017). BlindWays. Retrieved from http://www.perkins.org/solutions/featured-products/blindways

BlindWays uses GPS technology to get a user who is blind or has low vision to within 30 feet of their destination. This app uses topographical clues and data sourced from volunteers to help guide the app user to their destination. The idea is to close the gap left by traditional GPS navigation and help users find their exact location quicker and with more accuracy.

Rego, Nelson. (November 13, 2017). Developer's app helps visually impaired navigate. Cool

Blind Tech. Retrieved from https://coolblindtech.com/ developers-app-helps-visually-impaired-navigate/ 
The AWARE app for the visually impaired uses iBeacon hardware for audible wayfinding. This app provides indoor directions and visual descriptions to the user, and it can be modified based on user needs to be completely audio, high contrast with large fonts, or used with a braille display. The AWARE app provides detailed descriptions of the user's surroundings, as well as turn-by-turn directions.

Rego, Nelson. (March 2, 2018). Microsoft's new soundscape app helps the visually impaired

navigate cities. Cool Blind Tech. Retrieved from https://coolblindtech.com/ microsofts-new-soundscape-app-helps-visually-impaired-navigate-cities/

Soundscape uses 3D audio technology to map landmarks through audio cues. This app can describe different points of interest and landmarks as the user passes by them. The 3D navigation helps the user to develop a full picture of the setting, while allowing them to make navigational decisions on their own based on their surroundings.

Right-Hear. (2018). An accessibility solution for people who are blind or visually impaired.

Retrieved from https://right-hear.com/

Right-Hear provides indoor navigation assistance to individuals who are blind or visually impaired. It provides orientation and location information, alerts - including the presence of obstacles in the path - and live assistance if necessary. The app is free to users and available for Android and iOS devices. Buildings must be equipped with beacons for the use of this app. Building owners will have access to a content management platform that allows them to update alerts or navigational information.

Royal National Institute of Blind People. (September 3, 2015). NowNav - App of the month, $\underline{2015}$

September, 2015. Retrieved from https://www.rnib.org.uk/app-week-september-

NowNav announces turn-by-turn directions, surrounding street names and addresses, and user-defined destinations or waypoints. The compass on the NowNav app keeps up with the user as they move, ensuring that they are facing the correct direction for instructions. NowNav is only available for Android devices, and it is $\$ 12.99$.

Sendero Group. (n.d.). Seeing Eye GPS. Retrieved on August 1, 2018 from http://www.senderogroup.com/products/seeingeyegps/index.html

Seeing Eye GPS is the result of a collaboration between Seeing Eye - guide-dog training services - and the Sendero Group. This app provides turn-by-turn directions to the user, and is available for iOS products in the U.S. and Canada. This app describes intersections to the user with clock-face directions and it can be used for both pedestrian and vehicle routes. The Seeing Eye GPS app has a LookAround wand that allows the user to hold their phone up and scan the area for a verbal description of their 
surroundings. Nearby points of interest and intersections are announced automatically. The Seeing Eye GPS can be downloaded for a free one-month trial, but requires a subscription after the first month - $\$ 9.99$ for 30 days or $\$ 69.99$ for one year.

Venkat. (February 7, 2017). BeAware: A new app that helps visually impaired people navigate.

Assistive Technology Blog. Retrieved on August 1, 2018 from

http://assistivetechnologyblog.com/2017/02/beaware-a-new-app-that-helps-

visually-impa

Ired-people-navigate.html

BeAware is a navigation app that utilizes beacons placed throughout a location to guide the user and are primarily used for the purpose of obstacle avoidance. The app alerts the user immediately when they are approaching an obstacle. These alerts are sent either to the user's smartphone or smartwatch. The technology can be used indoor or outdoor depending upon where the beacons are set up. One Sense, the developers of BeAware, are working to expand this product beyond the United States. This app is only available on iOS devices. The cost of the app is free, but the cost of the beacons can vary.

Wayfindr. (March, 2018). Wayfindr. Retrieved on August 1, 2018 from https://www.wayfindr.net/

Wayfindr is an audio indoor navigation system that utilizes Bluetooth low energy beacons. The product is targeted to business that can install the beacons throughout their buildings for use by blind or low-vision travelers. This product is being used in several countries and they are trying to expand to make for simplified indoor navigation for travelers.

Wayfindr, in partnership with the International Telecommunication Union (ITU), also launched an eLearning Course on accessible audio navigation. This course is meant to increase awareness of the need for installing audio navigation throughout the world. The course provides information about visual impairment, orientation and mobility, and the steps required to design and install audio navigation systems. Wayfindr also provides a list of certified people and organizations to assist in development within its eLearning Course. This is an additional resource for an overview of the course: http://www.wayfindr.net/wp-content/uploads/2018/09/Course-Intro-3-September2018.pdf

Woodwill, Gary. (October 5, 2016). 9 outdoor navigation apps for people with visual impairments. Float. Retrieved from https://gowithfloat.com/2016/10/ 9-outdoor-navigation-apps-people-visual-impairments/

Ariadne is an app that senses vibrations from tapping on the street to send a vibration to the user's iPad, letting them know when they have safely crossed a street, as well as alerting the user to bus or train stops. Be My Eyes utilizes sighted people who communicate with the app user via live video connection. These sighted volunteers can 
provide visual descriptions to the visually impaired app user. BlindSquare uses GPS and data from Foursquare to share relevant location information with the app user.

GetThere provides navigational guidance before and after each intersection. Users can ask GetThere for location information and descriptions of intersections by shaking the mobile device. One useful feature of GetThere is the notification provided when the user is approaching their destination. Nearby Explorer uses the device's map and GPS for navigation, and allows the user to select from 18 location-related announcements anywhere in the United States or Canada. Talking Goggles uses video stream to constantly check for familiar images, which it announces to the user once identified.

\section{Crosswalk Assistance}

National Cooperative Highway Research Program. (2009). Appedix D: Purpose of the Retrieved prioritization tool. In Accessible Pedestrian Signals: A Guide to Best Practices. from http://www.apsguide.org/appendix d purpose.cfm

Municipalities often have to prioritize the installation of accessible pedestrian signals (APS) at existing traffic signals. The prioritization tool provides a number characteristic to aid in determining what intersections or crosswalks are to be prioritized to be made accessible. It is important to consider the process and potential problems of crossing a street at a designated intersection for those who are blind or visually impaired. The street-crossing process is comprised of: locating the street, recognizing the street, assessing the intersection, and finally crossing the street. At a typical crosswalk where the pedestrian must press a button and wait for the signal, individuals with vision impairment may face problems determining when the crosswalk is activated, what the trajectory of the vehicles is (especially with low traffic), or awareness of the presence of a crosswalk button if this is an intersection that is new to the pedestrian.

The prioritization tool is comprised of three worksheets used to detail the characteristics and features of an intersection (the appendix goes into great detail regarding the variables involved in the intersection and crosswalk configuration). These worksheets each include a rating system and are used to determine the specific rating for each crosswalk, with a higher score meaning a higher need/priority for installing APS.

Neate, Gavin \& Heaton, Sam. (September 29, 2017). Button by Neatebox. Disability United.

\section{Retrieved from http://disabilityunited.co.uk/2017/09/button-by-neatebox/}

Button provides hands-free access to electronic crosswalk systems. This app can be used to initiate a crosswalk without having to locate the crosswalk button. App users can find the crosswalk and square up to cross while initiating the cross signal on their phone, allowing for more time to prepare to cross the intersection. The phone will begin to vibrate in the user's hand once the cross signal is initiated. This app is currently only available in parts of the UK, but they are hoping to expand depending upon demand. 
Users can download the free app and request that certain venues be set up with the Button system. Neatebox will then contact local authorities and set up the system for the Button user.

Peters, Adele. (August 12, 2015). With your help, this app can make ordinary walk signs accessible to the blind. Fast Company. Retrieved from

https://www.fastcompany.com/ 3049726/with-your-help-this-app-can-make-ordinary-walk-signs-accessible-tothe-blind

SeeLight is an app that makes crosswalks accessible for blind or visually impaired users. The app informs the user of how much time is left for the crosswalk signal. The app data is crowdsourced as well as generated by city governments. The data is generated when a user maps out their own neighborhood crosswalks. They can measure the time it takes to cross a street, and they can enter detailed information about the individual intersections.

Ross Atkins Associates. (2015). Responsive Street Furniture. Retrieved from http://www.rossatkin.com/wp/?portfolio=responsive-street-furniture

Created in partnership with UK landscaping development company Marshalls, Responsive Street Furniture aims to create smart cities that respond to the needs of the individual. The idea is that Responsive Street Furniture will be installed throughout cities and will communicate with pedestrians via a phone app. The app user can design their profile and select from a number of needs based upon their disability or preferences. This could look like street lights brightening overhead for someone who has low vision; audio platforms that automatically direct pedestrians at crosswalks and inform them of landmarks as they pass by; or crosswalk times extended if someone requires more time to cross the street. The furniture would also include fold-up benches and seats that attach to the exterior of buildings so that someone who might be fatigued can be pointed to the direction of one of the various chairs to rest.

Tuvie. (May 4, 2011). Disability crosswalk system to help visually impaired people cross the

street safely. Retrieved from http://www.tuvie.com/disability-crosswalk-system-tohelp-visually-impaired-people-cross-the-street-safelyl

The Disability Crosswalk is activated by pressure placed on a pad that is located on the ground near the crosswalk. The crosswalk system will then verbally tell the pedestrian how fast vehicles are passing in the street and alert them when the vehicle is stopped or there are no vehicles present. This crosswalk system also has an LED panel that alerts drivers when a pedestrian is trying to cross the street

Umbrellium Ltd. (2018). Starling Crossing: Responsive road infrastructure. Retrieved from

http://umbrellium.co.uk/initiatives/starling-crossing/ 
Starling Crossing (Stigmergic Adaptive Responsive Learning) is a responsive road surface that was developed by Umbrellium Ltd. in the UK. This intelligent crosswalk uses visual designs typical of crosswalks in the area, and will appear when needed based on car, bicycle, and pedestrian traffic needs. These patterns are generated by embedded LEDs in the road surface, and the area around the crosswalk region is monitored by video camera. Crosswalks will be made to accommodate the needs of pedestrians in terms of width, angle, and length of time visible on the roadway.

Winkless, Laurie. (May 28, 2017). Using technology to help visually-impaired people navigate

cities. Forbes. Retrieved from

https://www.forbes.com/sites/lauriewinkless/2017/03/28/

using-technology-to-help-visually-impaired-people-navigatecities/\#58905c0171d5

ZebraX is a prototype app collaboratively developed by British and Italian scientists to create technology to assist visually impaired people cross at non-signaled crosswalks. The app is designed to detect the presence of a crosswalk and provides an auditory cue to alert the user. A combination of sounds and vibrations guide the user to the edge of the crosswalk.

\section{Transit Apps}

Be My Eyes. (January 22, 2018). Be My Eyes and Moovit join forces to make public transit

more accessible. Retrieved from https://www.bemyeyes.com/newsroom/be-my-

eyes-

and-moovit-join-forces-to-make-public-transit-more-accessible

Moovit is a popular transit app created by the data and analytics company of the same name. Be My Eyes, as described previously in further detail, is an app used to assist blind and visually impaired users in various aspects of daily living. The partnership between these companies seeks to improve knowledge across the areas of accessibility and transportation. The idea is that Moovit app users will be able to access Be My Eyes via the Moovit menu.

Cameron, Lori. (May 21, 2018). New app helps visually impaired passengers navigate bus

routes. IEEE Computer Society. Retrieved from https://publications.computer.org/ pervasive-computing/2018/05/21/public-transit-assistant-app-blind/

Developed by researchers at the University of California, Santa Cruz, a new public transit assistant app helps blind people navigate bus routes. The app is currently being called public transit assistant (PTA). This app, currently in its prototype stage, will 
function with or without internet or GPS, but just requires the user to be within range of a wi-fi access point. These can be installed at buses or bus stops. While a passenger is waiting at a bus stop, they will receive a notification when their bus is approaching. The passenger is then notified in advance - at the stop prior to their destination - when they are approaching their desired bus stop so as to allow for time to request the stop. This app is aimed at solving the problem of GPS inaccuracy by guiding the user right to the stop. This app was tested by four visually impaired users who all gave it good reviews. These participants requested that the following issues be considered in future editions of this app:

- Pointing out the exact distance between where people wait for the bus and the location of the bus access point.

- Identifying whether bus stops have benches to avoid searching for a bench if there is not one present. 